\title{
A Case of Canine Multiple Inflammatory Colorectal Polyps Treated by Endoscopic Polypectomy and Argon Plasma Coagulation
}

\author{
Atsushi TSUKAMOTO ${ }^{1)}$, Koichi OHNO ${ }^{1) *}$, Mitsuhiro IRIE ${ }^{1)}$, Aki OHMI ${ }^{1)}$, Shingo MAEDA ${ }^{1)}$, Ko NAKASHIMA ${ }^{1)}$, \\ Kenjiro FUKUSHIMA ${ }^{1)}$, Yasuhito FUJINO ${ }^{1)}$, Kazuyuki UCHIDA ${ }^{2)}$ and Hajime TSUJIMOTO ${ }^{1)}$ \\ ${ }^{1)}$ Department of Veterinary Internal Medicine, Graduate School of Agricultural and Life Sciences, The University of Tokyo, 1-1-1 \\ Yayoi, Bunkyo-ku, Tokyo 113-8657, Japan \\ ${ }^{2)}$ Department of Veterinary Pathology, Graduate School of Agricultural and Life Sciences, The University of Tokyo, 1-1-1 Yayoi, \\ Bunkyo-ku, Tokyo 113-8657, Japan
}

(Received 31 August 2011/Accepted 9 November 2011 /Published online in J-STAGE 22 November 2011)

ABSTRACT. Endoscopic polypectomy and argon plasma coagulation (APC) were performed in a refractory case of inflammatory colorectal polyps in a 7-year-old male Miniature Dachshund. Colonoscopic examination revealed a large sessile polyp and multiple diffuse small polyps, localized to the descending colon and rectum. The case showed a poor therapeutic response to prednisolone and cyclosporine. Under anesthesia, piecemeal resections were performed by polypectomy. APC was carried out to cauterize the polyp remnants. After treatment, reduction of the lesions and the improvement in clinical signs were observed, without recurrence of lesions for at least 10 months. Endoscopic treatment by polypectomy and APC is suggested to be a therapeutic option for refractory cases of inflammatory colorectal polyps in dogs.

KEY WORDS: canine, endoscopic treatment, immunosuppressive therapy, inflammatory polyp, Miniature Dachshund.

doi: 10.1292/jvms.11-0404; J. Vet. Med. Sci. 74(4): 503-506, 2012

Colorectal polyps in dogs come in a variety of forms as pedunculated, sessile, or lobulated. These polyps may be derived from neoplasms such as adenomatous polyps, or can be non-neoplastic lesions like inflammatory polyps [11, $13,14]$. We recently reported that inflammatory colorectal polyps are common in the Miniature Dachshund and typically form multiple diffuse polyps localized to the colon or rectum [8]. Immunosuppressive therapy with prednisolone and cyclosporine is suggested to be an effective treatment for the reduction of polyps and also amelioration of their associated clinical signs [8]. But in a few cases, the medical treatment results in poor therapeutic response, and requires physical removal of the polyps. Radical surgeries, such as the rectal pull-through technique, and endoscopic treatments have been reported for the resection of colorectal polyps in dogs $[2,3,6,12]$. As an endoscopic treatment, polypectomy has been performed clinically in dogs for the resection of colorectal polyps and can be performed as an alternative to radical surgery [2]. However, the adaptation of polypectomy in dogs is limited to the treatment of pedunculated polyps since the method requires a stalk on the polyp to loop with the polypectomy snare. Polypectomy is not applied to the removal of small diffuse polyps as well.

Argon plasma coagulation (APC) is a device used for noncontact thermal coagulation of tissue which can be per-

\footnotetext{
*Correspondence to: Ohno, K., Department of Veterinary Internal Medicine, Graduate School of Agricultural and Life Sciences, The University of Tokyo, 1-1-1 Yayoi, Bunkyo-ku, Tokyo 113-8657, Japan.

e-mail: aohno@mail.ecc.u-tokyo.ac.jp

(C)2012 The Japanese Society of Veterinary Science
}

formed under endoscopy (Fig. 1). In humans, this method has been used for the endoscopic cauterization and hemostasis of gastrointestinal lesions [5]. Previous report in humans has described that APC is effective for the cauterization of multiple sessile colorectal polyps [1, 7]. In this report, we describe a refractory case of inflammatory colorectal polyps in Miniature Dachshund treated by endoscopic polypectomy and APC.

A 7-year-old neutered male Miniature Dachshund was referred to the Veterinary Medical Center of the University of Tokyo with a complaint of hematochezia. The dog's stool frequency was approximately 5 times a day. Rectal examination revealed roughness of the colorectal mucosa. General physical examination did not show any abnormalities in the dog. Additionally, the results of blood tests (CBC and blood biochemistry) and fecal examinations did not show any abnormalities.

Endoscopy was performed to examine the cause of gastrointestinal clinical signs. Colonoscopic examination revealed multiple diffuse small polyps localized to the colorectal mucosa approximately $3-5 \mathrm{~cm}$ from the anus. Endoscopic biopsy was performed to obtain sample specimens of the lesions; these were diagnosed histopathologically as inflammatory polyps. Initially, the dog was treated with prednisolone $(1 \mathrm{mg} / \mathrm{kg} P O, B I D)$ and cyclosporine (5 $\mathrm{mg} / \mathrm{kg} P O, S I D)$. Seventeen days after diagnosis, the frequency of hematochezia decreased. The dose of prednisolone was gradually reduced to $0.5 \mathrm{mg} / \mathrm{kg} S I D$, subsequent to the dose of $1 \mathrm{mg} / \mathrm{kg}$ SID for 2 weeks. After the dose reduction, clinical signs gradually worsened, and 90 days after the initial diagnosis, the dog showed severe tenesmus with hematochezia. Stool frequency was approximately 

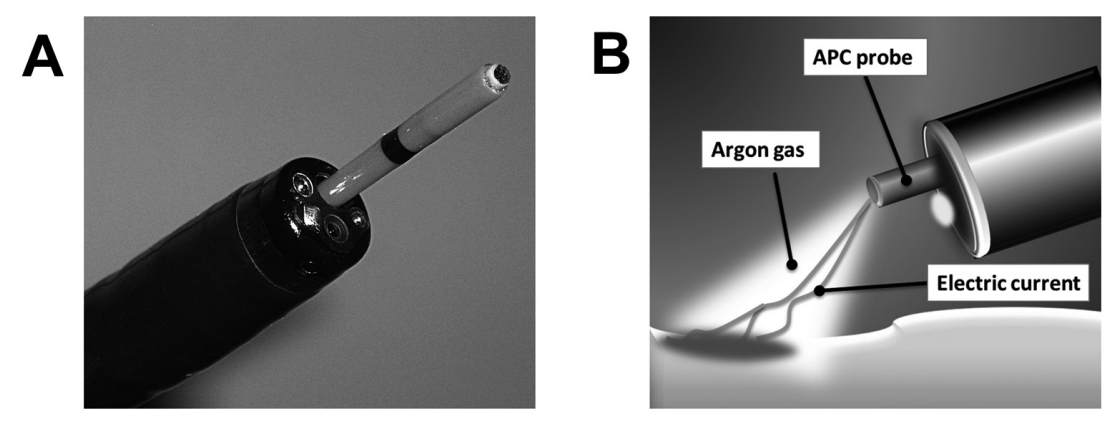

Fig. 1. Argon plasma coagulation (APC). (A) Argon plasma coagulator probe (ERBE Co.). (B) Schematic representation of APC cauterization in the gastrointestinal mucosa. Highfrequency electric current is applied with a jet of argon gas (plasma) through the probe and used to cauterize the surface of the mucosal lesion.

20 times a day. Colonoscopy was performed again for assessment of the lesions under general anesthesia induced by propofol and isoflurane. Colonoscopic examination revealed a large sessile polyp and small diffuse polyps localized to colorectal mucosa (Fig. 2A).

Since immunosuppressive treatment resulted in a poor therapeutic response and multiple diffuse polyps of variable size were present, endoscopic polypectomy with APC was performed for the physical removal of the polyps. Initially, polypectomy was performed via direct visualization of the polyp and placement of an electrosurgical snare on the mass, with a maximum power of $120 \mathrm{~W}$ (ICC 200, ERBE Co., Tubingen, Germany). However, since the stalk of the mass was often unclear, it was impossible to loop the snare around the stalk of polyps. Therefore, piecemeal resections were performed several times. Endoscopic findings after polypectomy are shown in Fig. 2B. The mass was not completely ablated, and it remained adhering to the mucosa with bleeding from the surface of the resected site. The small diffuse polyps also remained.

Following polypectomy, APC was performed endoscopically to remove the polyp remnants and for hemostasis after polypectomy. The APC 300 (ERBE Co.) was used at an argon flow rate of $1 \mathrm{l} / \mathrm{min}$ and high frequency power of $50 \mathrm{~W}$. The APC probe was moved close to the lesion sites, and cauterization was performed carefully to avoid contact with the surrounding tissue (Fig. 2C). Since the lesions were spread diffusely throughout the mucosa, APC cauterization was performed several times to remove the polyp remnants. After APC, the lesion was washed and insufflated through the endoscope to confirm the absence of perforated sites in the treated region.

An endoscopic view of the lesions after APC is shown in Fig. 2D. The large polyp was removed, with remnants of the thermally cauterized regions. The resected large mass was examined histopathologically and diagnosed as an inflammatory polyp, in line with the initial histopathological diagnosis. Prednisolone $(1 \mathrm{mg} / \mathrm{kg} E O D)$ and cyclosporine ( $5 \mathrm{mg} / \mathrm{kg}$ SID) were prescribed continuously.

From the following day, the dog showed prominent amelioration of clinical signs. Tenesmus was not observed, and only a small amount of hematochezia occurred, at a frequency of 1 in 5 defecations. The owner reported that there were no signs of complications, such as rectal bleeding or symptoms of perforation, immediately after endoscopic treatment. Colonoscopy was performed to check the treated region. Although the small polyps remained, there was a significant reduction in the lesions (Fig. 2E), when compared with the lesions pre-treatment. Dropout of thermally cauterized tissues was evident. Six weeks after endoscopic treatment, we rechecked the lesions endoscopically and confirmed that the lesions had not expanded. We followed the case for 10 months, with consecutive prednisolone (1 $\mathrm{mg} / \mathrm{kg} E O D)$ and cyclosporine $(5 \mathrm{mg} / \mathrm{kg} S I D)$ treatment. The gastrointestinal clinical sign of hematochezia had been successfully controlled in this period. Colonoscopic findings in the rectum 10 months after endoscopic treatment revealed no progression of the rectal lesions (Fig. 2F).

We have performed endoscopic polypectomy and APC in a case of inflammatory colorectal polyps in a Miniature Dachshund. In the present case, physical removal of polyps was required, because prominent amelioration of clinical signs was not achieved by immunosuppressive therapy alone. Radical surgeries such as the pull-through technique are often performed for the complete removal of colorectal polyps $[6,8,12]$. However, in some cases, other treatments may be selected by considering the anatomical location of the lesion, the histopathological type of the lesion, or postsurgical complications. We selected endoscopic treatment because the gross appearance of lesions was a mixture of multiple sessile polyps, and the owner requested amelioration of gastrointestinal clinical signs with a less invasive treatment. As a result, the case showed prominent improvement in clinical signs and reduction of polyps without recurrence for 10 months. Polypectomy is difficult for complete resection of sessile polyps because the resection site for polypectomy is the stalk of the mass. In contrast, APC can be used for cauterization from the surface of polyps. Along with radical surgeries, combination of endoscopic polypectomy and APC may help the induction treatment for inflammatory colorectal polyps in Miniature Dachshund.

Present case was successfully managed the clinical signs 

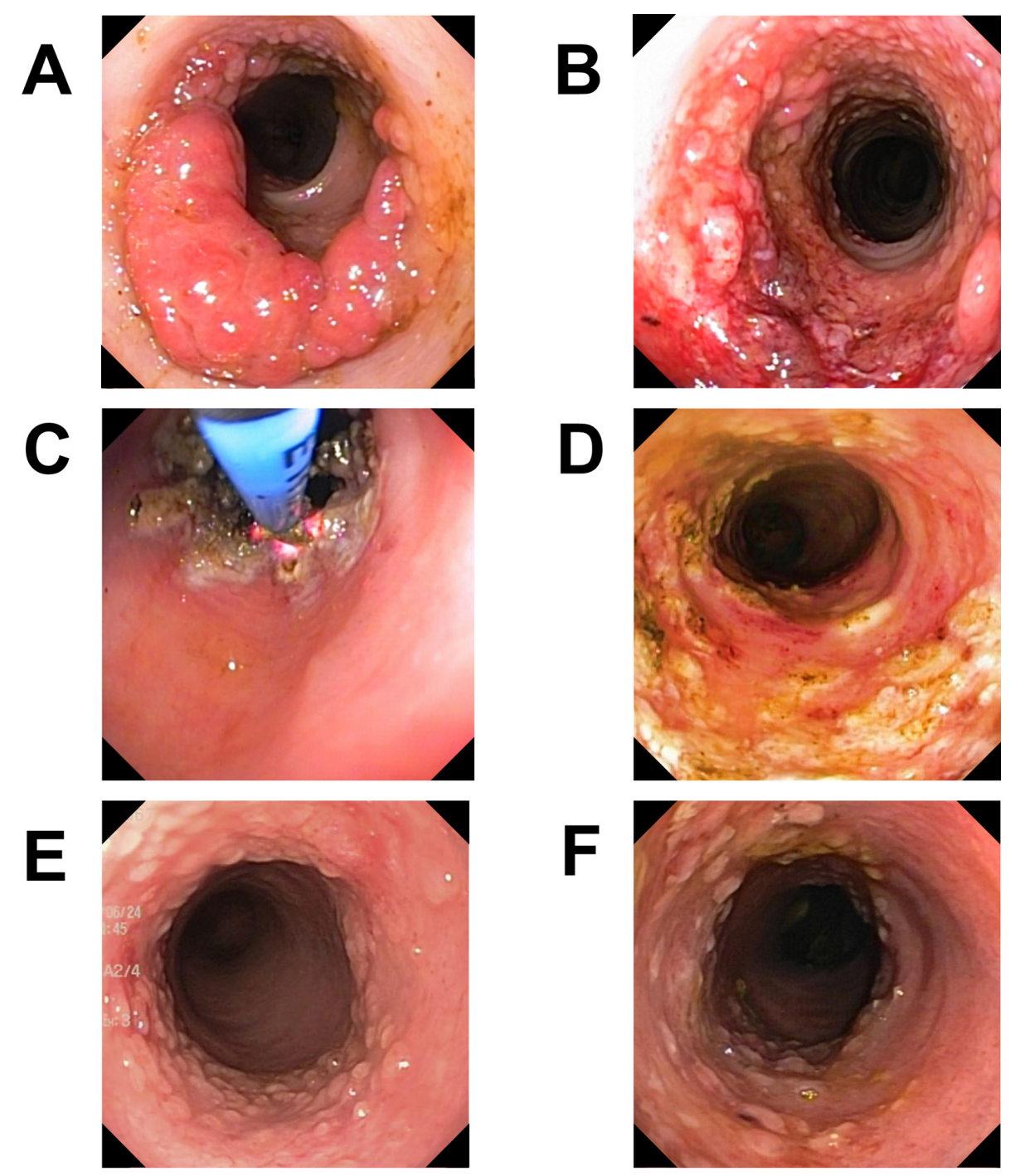

Fig. 2. Endoscopic findings in the rectal region before and after endoscopic treatment in a dog. (A) Ninety days after initial diagnosis. Large sessile polyps and multiple diffuse small polyps were observed. (B) Endoscopic view of the lesions immediately after performing polypectomy. Polyp remnants were observed with bleeding from the resected area. (C) APC therapy (D) Colorectal lesions immediately after APC therapy (E) Two weeks after endoscopic treatment. (F) Ten months after endoscopic therapy.

without recurrence for 10 months. One of the reasons for the long successful management is that significant reduction of lesions was accomplished with an endoscopic treatment. Another may be attributed to the consecutive immunosuppressive treatment. As aim of the endoscopic treatment for the colorectal polyp is the reduction of lesion, rather radical cure, combined application of immunosuppressive therapy may be important for the management of the disease after endoscopic treatment.

In the present case, no complications were observed after endoscopic polypectomy and APC. Rectal bleeding and gastrointestinal perforation are considered as complication of the endoscopic treatments $[3,5,10]$. In humans, the com- plications after APC are suggested to be rare, compared with other thermal methods [5]. During APC treatment, care must be taken to ensure that the probe does not come into contact with the tissue, and continuous energization in the same region should be avoided. The appropriate power setting and argon flow rates is required, which are assessed according to the indications for therapy [5]. In the present case, the flow rate and power setting were chosen by referring to human reports and adjusted carefully $[1,5,7,9]$. It is said that rectal bleeding may be caused as complications of polypectomy [10]. In the present case, sites of bleeding after polypectomy were cauterized with APC. Therefore, APC may be effective for hemostasis after polypectomy, 
and combining APC with polypectomy may minimize the risk of complications.

In humans, APC has been applied to neoplastic gastrointestinal lesions such as colorectal adenomatous polyps or early gastric cancer [4, 9]. A previous report in humans suggested that treatment with APC reduces recurrence after piecemeal resection of neoplastic colorectal polyps [1]. Further investigations with long-term follow-ups are required to confirm the application of APC in neoplastic colorectal polyps in dogs.

In summary, we have shown the use of endoscopic polypectomy and APC in a case of refractory inflammatory colorectal polyps in the Miniature Dachshund. The combination of polypectomy and APC is suggested to be a viable therapeutic option for refractory cases of inflammatory colorectal polyps.

ACKNOWLEDGMENT. We would like to thank Dr. Mayumi Hisano (Animal Hospital Health Pet) for introducing us the case described in this report.

\section{REFERENCES}

1. Brooker, J. C., Saunders, B. P., Shah, S. G., Thapar, C. J., Suzuki, N. and Williams, C. B. 2002. Treatment with argon plasma coagulation reduces recurrence after piecemeal resection of large sessile colonic polyps: a randomized trial and recommendations. Gastrointest. Endosc. 55: 371-375. [Medline] [CrossRef]

2. Foy, D. S. and Bach, J. F. 2010. Endoscopic polypectomy using endocautery in three dogs and one cat. J. Am. Anim. Hosp. Assoc. 46: 168-173. [Medline]

3. Holt, P. E. 2007. Evaluation of transanal endoscopic treatment of benign canine rectal neoplasia. J. Small Anim. Pract. 48: 17-25. [Medline] [CrossRef]

4. Kitamura, T., Tanabe, S., Koizumi, W., Mitomi, H. and Saigenji, K. 2006. Argon plasma coagulation for early gastric cancer: technique and outcome. Gastrointest. Endosc. 63: 48-54. [Medline] [CrossRef]
5. Malick, K. J. 2006. Clinical applications of argon plasma coagulation in endoscopy. Gastroenterol. Nurs. 29: 386-391. [Medline] [CrossRef]

6. Morello, E., Martano, M., Squassino, C., Iussich, S., Caccamo, R., Sammartano, F., Zabarino, S., Bellino, C., Pisani, G. and Buracco, P. 2008. Transanal pull-through rectal amputation for treatment of colorectal carcinoma in 11 dogs. Vet. Surg. 37: 420-426. [Medline] [CrossRef]

7. Nozoe, Y., Araki, Y., Fukushima, H. and Shirouzu, K. 2004. A case of argon plasma coagulation therapy for hemorrhagic rectal tumor in a highly aged patient. Kurume Med. J. 51: 159161. [Medline] [CrossRef]

8. Ohmi, A., Tsukamoto, A., Ohno, K., Uchida, K., Nishimura, R., Fukushima, K., Takahashi, M., Nakashima, K., Fujino, Y. and Tsujimoto, H. 2011. A retrospective study of inflammatory colorectal polyps in miniature dachshunds. J. Vet. Med. Sci. (in press). [Medline] [CrossRef]

9. Regula, J., Wronska, E., Polkowski, M., Nasierowska-Guttmejer, A., Pachlewski, J., Rupinski, M. and Butruk, E. 2003. Argon plasma coagulation after piecemeal polypectomy of sessile colorectal adenomas: long-term follow-up study. Endoscopy 35: 212-218. [Medline] [CrossRef]

10. Repici, A. and Tricerri, R. 2004. Endoscopic polypectomy: techniques, complications and follow-up. Tech. Coloproctol. 8: s283-290. [Medline] [CrossRef]

11. Seiler, R. J. 1979. Colorectal polyps of the dog: a clinicopathologic study of 17 cases. J. Am. Vet. Med. Assoc. 174: 72-75. [Medline]

12. Shida, T., Maruo, T., Suga, K., Kawamura, H., Takeda, H., Sugiyama, H., Isikawa, T., Inoue, A., Yamada, T., Ito, T., Madarame, H., Kayanuma, H. and Suganuma, T. 2008. Rectal Mucosal Pull-Through Surgical Technique for Canine Rectal Multiple Tumor. Jpn. J. Vet. Aneth. Surg. 39: 11-16. [CrossRef]

13. Valerius, K. D., Powers, B. E., McPherron, M. A., Hutchison, J. M., Mann, F. A. and Withrow, S. J. 1997. Adenomatous polyps and carcinoma in situ of the canine colon and rectum: 34 cases (1982-1994). J. Am. Anim. Hosp. Assoc. 33: 156-160. [Medline]

14. van Der Gaag, I. 1988. The histological appearance of large intestinal biopsies in dogs with clinical signs of large bowel disease. Can. J. Vet. Res. 52: 75-82. [Medline] 